\title{
OBSERVATIONS UPON THE CALCIUM AND PHOSPHORUS METABOLISM IN A CASE OF ACROMEGALY SHOWING MARKED OSTEOPOROSIS
}

\author{
BY W. DF M. SCRIVER AND A. H. BRYAN \\ (From the Department of Medicine, McGill Unizersity Clinic, \\ Royal Victoria Hospital, Montreal)
}

(Received for publication October 19, 1934)

Our interest in the mineral metabolism in acromegaly was aroused by the remarkable generalised rarefaction of the bones shown in $x$-ray films of one of our patients in an advanced state of this disease. Since we have been unable to find in the literature any record of metabolic studies in acromegalics more recent than that of Bergeim, Stewart and Hawk (1) in 1914, and in view of the important advances of the past few years in the study of calcium and phosphorus metabolism, particularly in certain pathological conditions of bone, we feel that the observations which we have been able to make on this patient are worthy of recording.

\section{CASE HISTORY}

T. W., a Jewess 51 years of age, was admitted to the metabolism service of the Royal Victoria Hospital on

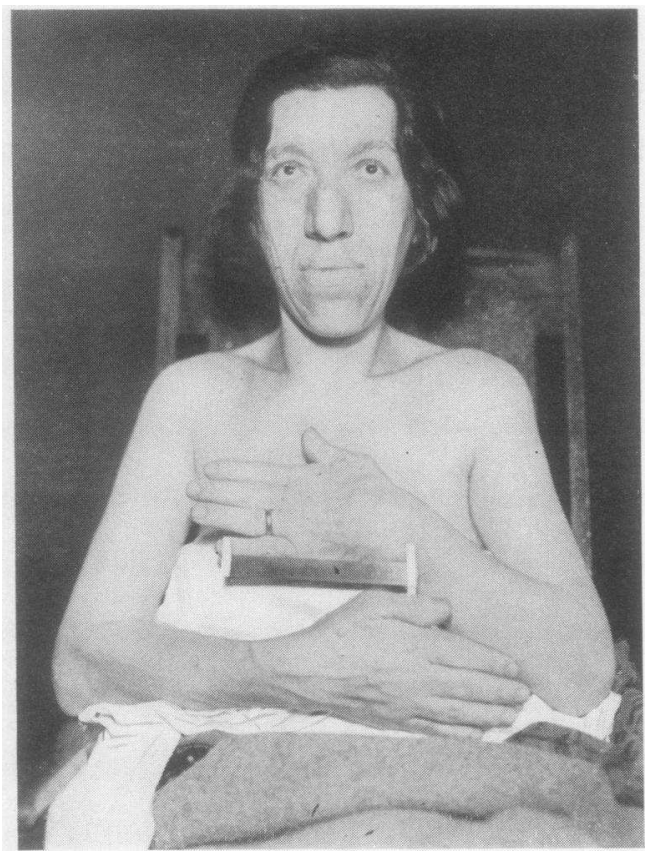

FI(i. 1.
April 6th, 1932, complaining of weakness and failing vision. Her appearance was that of an advanced acromegalic (Figure 1).

According to the history obtained from the patient herself, she was born in Russia, and in her early life was a strong, healthy, apparently normal girl. At the age of eleven she began to be troubled with severe generalized headaches which ceased coincidentally with the onset of menstruation two years later. She was married at 20 and had two normal children, in her $22 \mathrm{~d}$ and 24th year respectively.

At the age of 29 she came to Canada; she remembers that at this time she was admired for her general physique and attractive appearance. Until she reached the age of 32 her menstruation had always been normal, but at this time it ceased completely and finally. In the following year, several years after the death of her first husband, she married again, but had no further pregnancies. Shortly after this. her sister, who had not seen her for four years, failed to recognize her, as her fea-

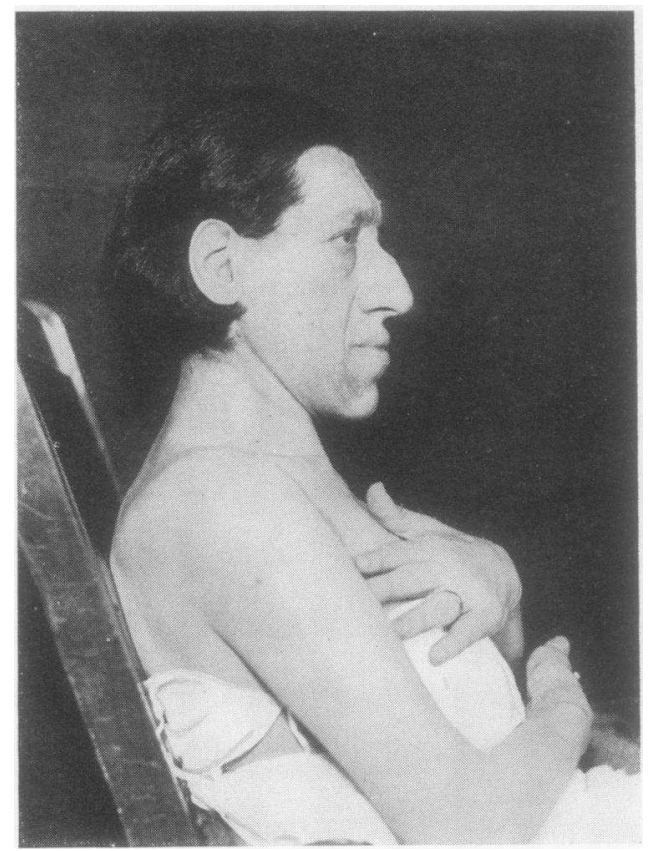

Fig. 2.

Figs. 1 and 2. Appearance of Patient in 1932. 


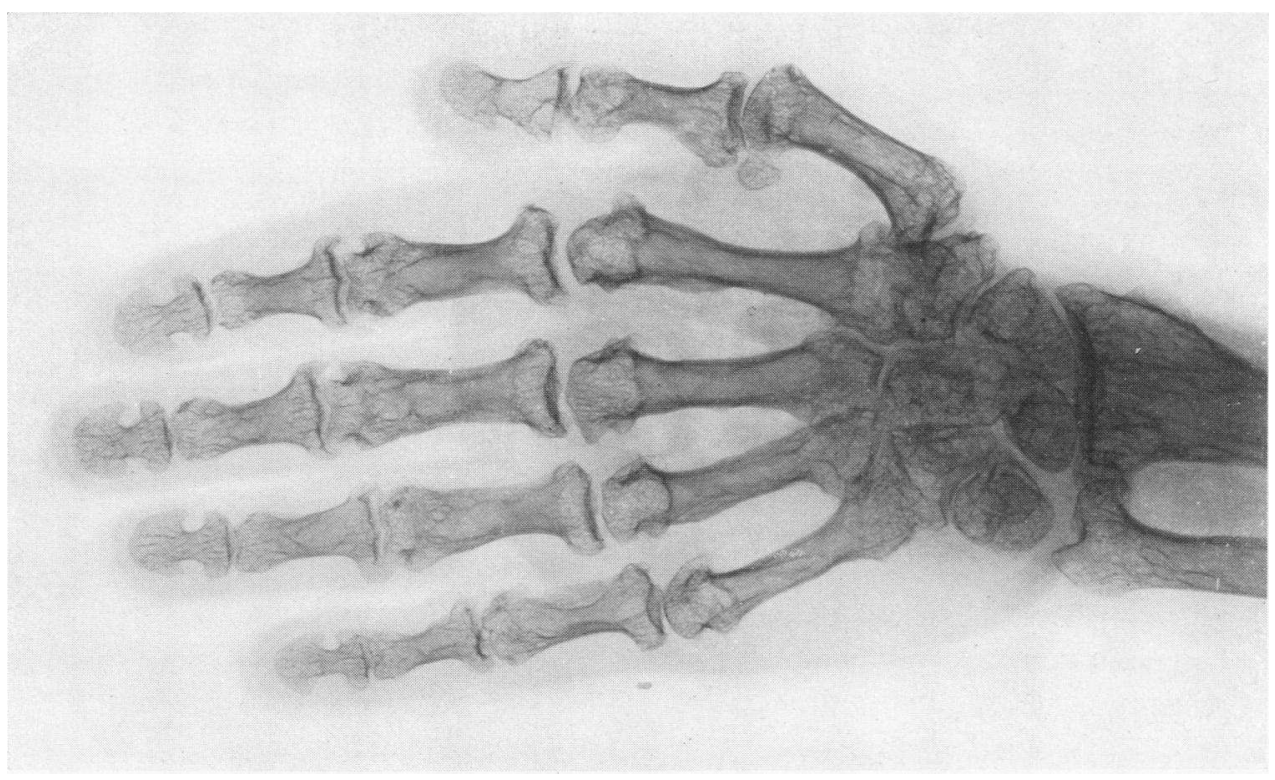

Fig. 3. X-Ray of Right Hand.

tures had enlarged, and changed in appearance, as also had her hands. A photograph taken in her 26th year shows evidences of early acromegaly; the characteristic appearance is well established in one taken four years later. She states that her face has been changing progressively since the onset. At the age of 39 she was forced to wear a larger size of shoes, but there has been no change in size since then.

In her late forties a generalized feeling of weakness began which has been progressive since, especially in the legs; she now has to walk with a cane. When she was about 48 her eyesight began to fail, and for the two years preceding admission to hospital she has been unable to read.

Her hair, which used to be oily, has now become dry and coarse; the skin is less greasy than it was, but is not dry.

In the physical examination the most striking feature is the advanced acromegalic appearance; the features are large and coarse, with heavy overhanging supraorbital ridges, broad cheek bones, large nose, thick lips, and enormous projecting mandible. The hands and feet are also much enlarged, and typically spade shaped. The chest is definitely increased in anteroposterior diameter, the supra- and infra-clavicular fossae being very pronounced. The pelvic organs are also large; neither external nor internal genitalia show the changes usually associated with the menopause. The pelvic hair has the normal female type of distribution, and is moderately coarse ; that of the head is decidedly coarse, dry and very abundant; the axillae, however, have but scanty hair.

While the optic fundi appear normal, vision in the left eye is $6 / 30$, in the right $6 / 20$; the visual fields show a bitemporal hemianopsia. Basal metabolic rate, averaged from several determinations, is +3 (approximately 1500 calories per 24 hours). Blood chemistry is normal for the main constituents. The urine is negative. There is a moderate degree of anaemia, with $3,400,000$ erythrocytes, and 60 per cent haemoglobin (8.4 grams per $100 \mathrm{cc}$.$) . The blood pressure averages 130$ systolic and 85 diastolic. There is nothing of importance in the other organs.

Numerous $x$-ray plates were made all of which showed a spongy osteoporotic appearance of the bones. The following is a somewhat abbreviated summary of the reports furnished by Dr. A. H. Pirie, Roentgenologist-inChief of the Royal Victoria Hospital.

Hand--The terminal phalanges have a corn sheaf appearance. The base of each middle phalanx is expanded and lipped, externally and internally. The trabeculae of the phalanges, metacarpal and carpal bones are opened out so as to form a wide network. There is a periosteal new growth of bone on the shaft of each proximal phalan $\mathrm{x}$ and metacarpal bone.

Foot-The trabeculae are opened up in all bones of the foot except the shafts of the metatarsals and the proximal phalanges. There is periosteal new bone formation in the shaft of the first left metatarsal bone.

Skull-Stereoscopic views show a great thickening of the calvaria, especially in the regions of the parietal bones. The thickening of the skull is like a dense spongework, and not solid ivory bone. The frontal sinuses and antra are especially large. The sella turcica is enlarged and presents an eroded appearance. Side views of the head show a great increase in the size of the bones of the face. The cervical vertebrae present a rarefied ground-glass appearance.

Lower extremitics-The bones are rarefied and irregular in outline, the trabeculae are opened up and form a sponge-like network, the spaces of which are larger than 
in normal bone. The lower ends of the femora at the metaphyses are flattened from before backward and broadened from side to side. The articular surface at the lower end of each femur is more irregular in outline than normal; such an appearance is observed in cases of osteoarthritis, but evidence of lipping, as in osteoarthritis, is absent. There is marked periosteal new bone formation in each femur, broadening the diameter of the shaft. The patellae are a little larger than usual.

Chest-The heart is under average size; the aorta, trachea, and diaphragm are negative. The trabeculae of the bones of the chest and clavicles present the openedout appearance of a meshwork.

\section{GENERAL METHODS}

The metabolic studies reported here were carried out during two different periods in hospital, at an interval of approximately one year, during which time the patient had been under observation in the Out-Patient Clinic, where no obvious changes in physical condition were noted. In May, 1932, Diet I was commenced, and the observations were carried out over three periods of three days each. Following this, Diet II was given and after a fore period of several days, observations were made for the same number of periods. The patient was readmitted in May, 1933, as we desired to see the effect of a diet still higher in calcium, with and without viosterol; accordingly observations were made over three periods during which she consumed Diet III, followed by two periods in which in addition she was given viosterol $(250 \mathrm{D})$ in the dose of twenty drops three times daily, and three periods with thirty drops at each dose.

The composition of the individual diets was as shown in Table I; it did not vary during the period under study. According to standard tables (2), Diets II and III were approximately neutral; Diet I, however, was found to have an excess acidity of approximately $18 \mathrm{cc}$. of normal acid, to counteract which sodium bicarbonate was given to the patient immediately after meals in dosage calculated to neutralize the excess acidity. At no time was the nitrogen balance on the negative side.

The nursing. dietetic and analytical methods used were the same as those clescribed in a previous communication (3).

\section{RESULTS}

The results of this investigation are summarized in Table II, in which the first two sets
TABLE I

Composition of diets

(Daily intake in grams or cubic centimeters)

\begin{tabular}{|c|c|c|c|}
\hline & $\underset{\text { I }}{\text { Diet }}$ & $\begin{array}{c}\text { Diet } \\
\text { II }\end{array}$ & $\begin{array}{l}\text { Diet } \\
\text { III }\end{array}$ \\
\hline 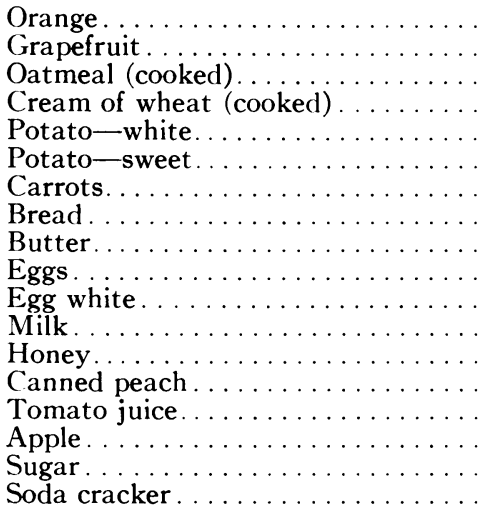 & $\begin{array}{r}140 \\
40 \\
2 * \\
81 \\
100 \\
18 \\
\\
150 \\
100 \\
32\end{array}$ & $\begin{array}{r}50 \\
100 \\
100 \\
120 \\
24 \\
2 * \\
0 \\
475 \\
17 \\
155\end{array}$ & $\begin{array}{r}50 \\
100 \\
100 \\
120 \\
24 \\
2 * \\
0 \\
675 \\
17 \\
155\end{array}$ \\
\hline 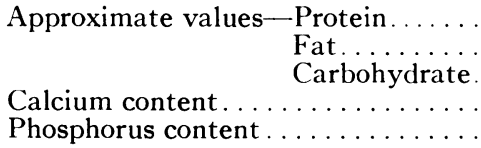 & $\begin{array}{r}50 \\
50 \\
200 \\
0.299 \\
0.533\end{array}$ & $\begin{array}{r}50 \\
50 \\
200 \\
0.810 \\
0.966\end{array}$ & $\begin{array}{r}57 \\
59 \\
217 \\
1.060 \\
1.259\end{array}$ \\
\hline
\end{tabular}

* Eggs were not weighed; those used were all approximately the same size.

of data represent the observations made in 1932 and the remaining sets of clata those made in 1933. It will be observed that the blood serum calcium and inorganic phosphorus remained fairly constant throughout all periods of investigation, the blood calcium values tending to range from normal to slightly below normal, while the inorganic phosphorus was slightly elevated.

From the standpoint of the balance of both calcium and phosphorus the important point is that, disregarding the periods in which viosterol was given, the balance was decidedly negative on the cliet affording the lowest intake of calcium and phosphorus, less negative on Diet II, while it became positive on the higher intake of Diet III. In Table III are summarized the reports of calcium and phosphorus balances in acromegaly which we have been able to find in the literature from the work of Schiff (4) in 1897, to the studies of Bergeim, Stewart and Hawk in 1914 (1). Our own figures are found in the first three sets of data. To make the results comparable, all values have been recalculated in terms of grams of calcium or phosphorus per diem. In only one 
TABLE II

Calcium and phosphorus metabolism. (In the case of diet, urine, and feces, figures represent the average for a single period of three days expressed in milligrams)

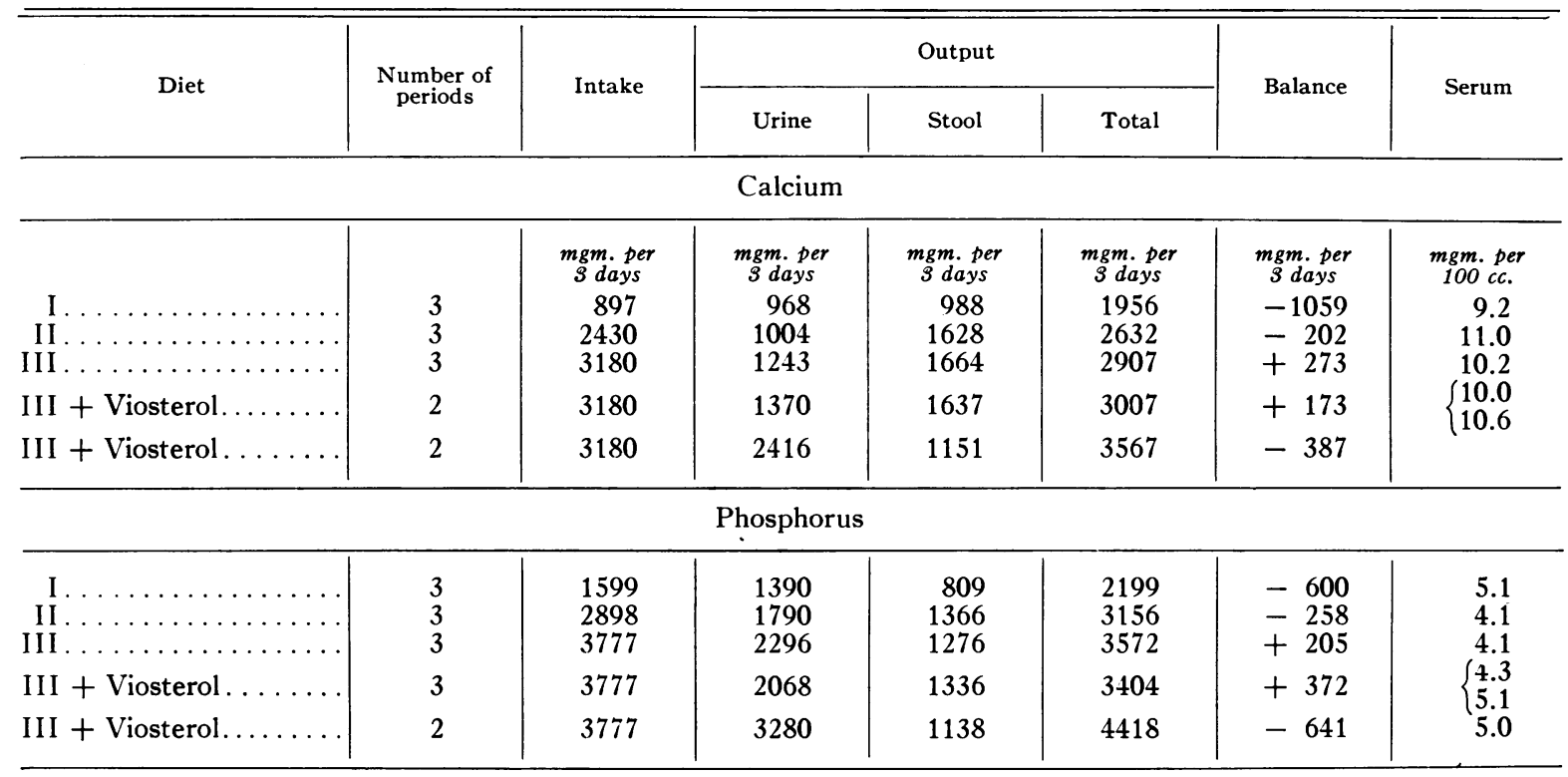

case reported completely enough to be included in the table was a negative balance found-that of Oberndörffer (7) reported in 1908, in which, with a calcium intake of 1.354 gram per diem the sub-

TABLE III

Summary of calcium and phosphorus metabolism data found in the literature. (Values represent the average for a single day expressed in milligrams of $\mathrm{Ca}$ and $P$.)

\begin{tabular}{|c|c|c|c|c|c|c|}
\hline \multirow{2}{*}{ Author } & \multirow{2}{*}{ Diet } & \multirow{2}{*}{ Intake } & \multicolumn{3}{|c|}{ Output } & \multirow{2}{*}{ Balance } \\
\hline & & & Urine & Stool & Total & \\
\hline \multicolumn{7}{|c|}{ Calcium } \\
\hline 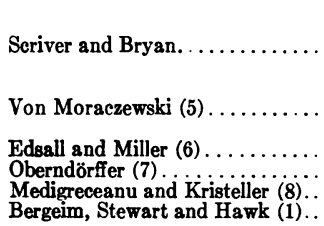 & $\begin{array}{c}\text { II } \\
\text { III } \\
\text { II }\end{array}$ & $\begin{array}{r}m g m . \\
299 \\
810 \\
1060 \\
1606 \\
2170 \\
1691 \\
1354 \\
1100 \\
1067\end{array}$ & $\begin{array}{r}m g m . \\
323 \\
335 \\
414 \\
329 \\
178 \\
6002 \\
409 \\
626 \\
114\end{array}$ & \begin{tabular}{r|}
$m g m$. \\
329 \\
543 \\
555 \\
526 \\
701 \\
872 \\
1571 \\
242 \\
781
\end{tabular} & $\begin{array}{r}m g m . \\
652 \\
878 \\
969 \\
855 \\
879 \\
1534 \\
1980 \\
868 \\
895\end{array}$ & $\begin{array}{r}-353 \\
+\quad 68 \\
+\quad 91 \\
+751 \\
+1276 \\
+157 \\
+626 \\
+\quad 232 \\
+172\end{array}$ \\
\hline \multicolumn{7}{|c|}{ Phosphorus } \\
\hline 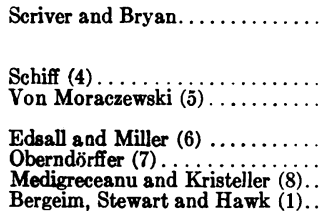 & $\begin{array}{r}\text { I } \\
\text { III } \\
\text { I } \\
\text { II }\end{array}$ & $\begin{array}{r}533 \\
966 \\
1259 \\
1120 \\
3478 \\
4269 \\
1385 \\
1001 \\
675 \\
750\end{array}$ & $\begin{array}{r}463 \\
597 \\
765 \\
742 \\
1704 \\
2022 \\
762 \\
628 \\
586 \\
400\end{array}$ & $\begin{array}{l}270 \\
456 \\
425 \\
285 \\
244 \\
288 \\
334 \\
356 \\
79 \\
235\end{array}$ & $\begin{array}{r}733 \\
1053 \\
1190 \\
1027 \\
1948 \\
2310 \\
1096 \\
984 \\
665 \\
635\end{array}$ & $\begin{array}{r}-200 \\
+\quad 87 \\
+\quad 69 \\
+\quad 93 \\
+1530 \\
+1959 \\
+\quad 289 \\
+\quad 17 \\
+\quad 10 \\
+115\end{array}$ \\
\hline
\end{tabular}

ject actually excreted 0.626 gram daily more than he ingested. In this same case the phosphorus balance was just barely positive (a retention of 0.017 gram per day). It will be observed on studying the figures that no case in the literature received a daily calcium intake as low as did our patient with Diets I and II; and that with Diet III, when her daily calcium intake was comparable to that fed by Medigreceanu and Kristeller (8) and by Bergeim, Stewart and Hawk (1), her daily retention was 0.091 gram as compared with their respective values of 0.232 gram and 0.172 gram. A study of the phosphorus intake summarized in Table II leads to similar considerations except that the case reported by Medigreceanu and Kristeller (8) on an intake of 0.675 gram of phosphorus a day, slightly higher than that afforded by our Diet I, remained in positive balance with a retention of 0.01 gram a day. In all studies except the present one, the intake of calcium and phosphorus has been so high that a positive balance might be expected in a normal individual (3).

After our subject had received Diet III for three periods of three days each, she was given viosterol, in addition, for five periods to observe its effect on the absorption of calcium and phosphorus. For the first two viosterol periods the 


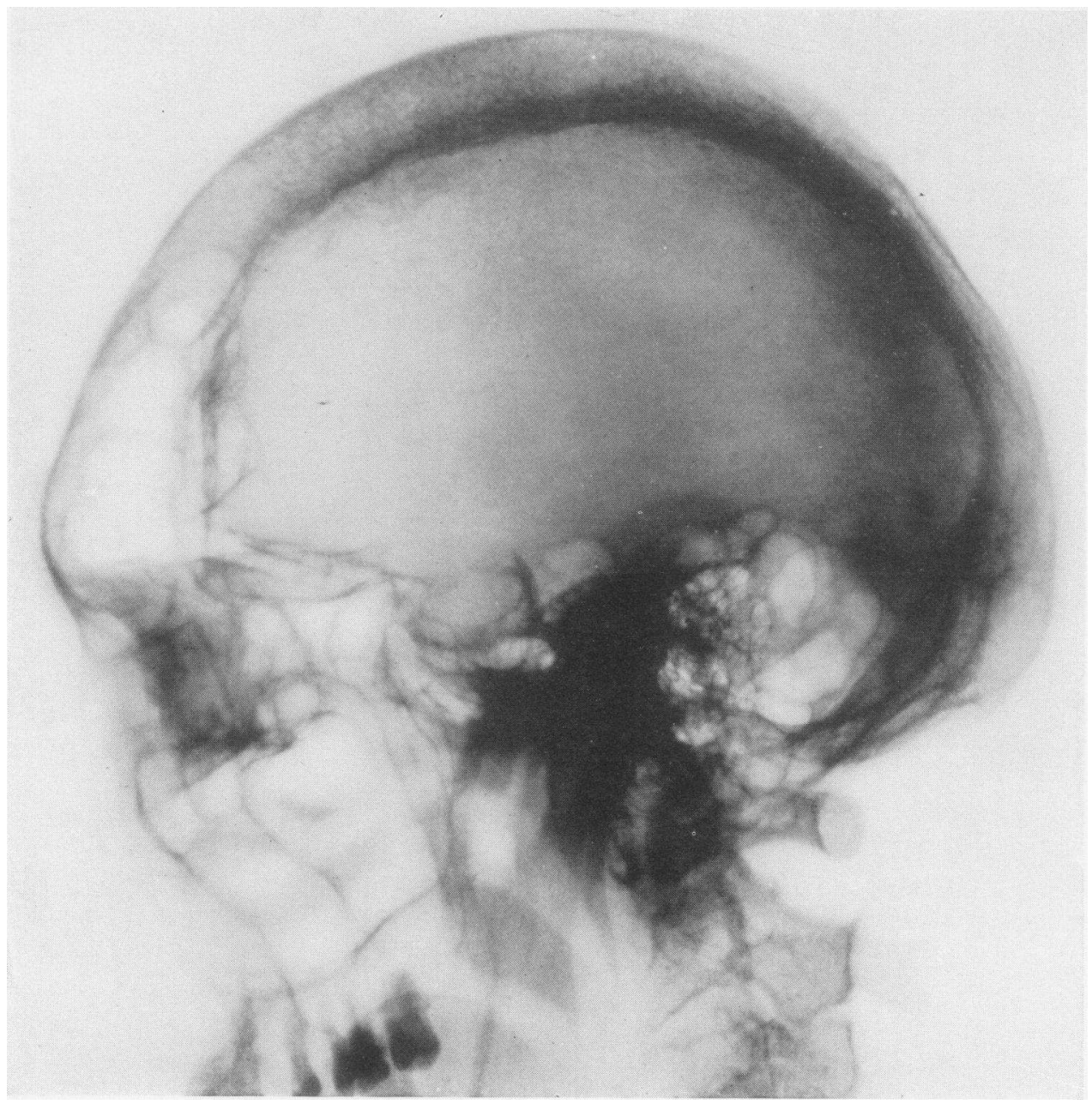

Fig. 4. X-Ray of Skull.

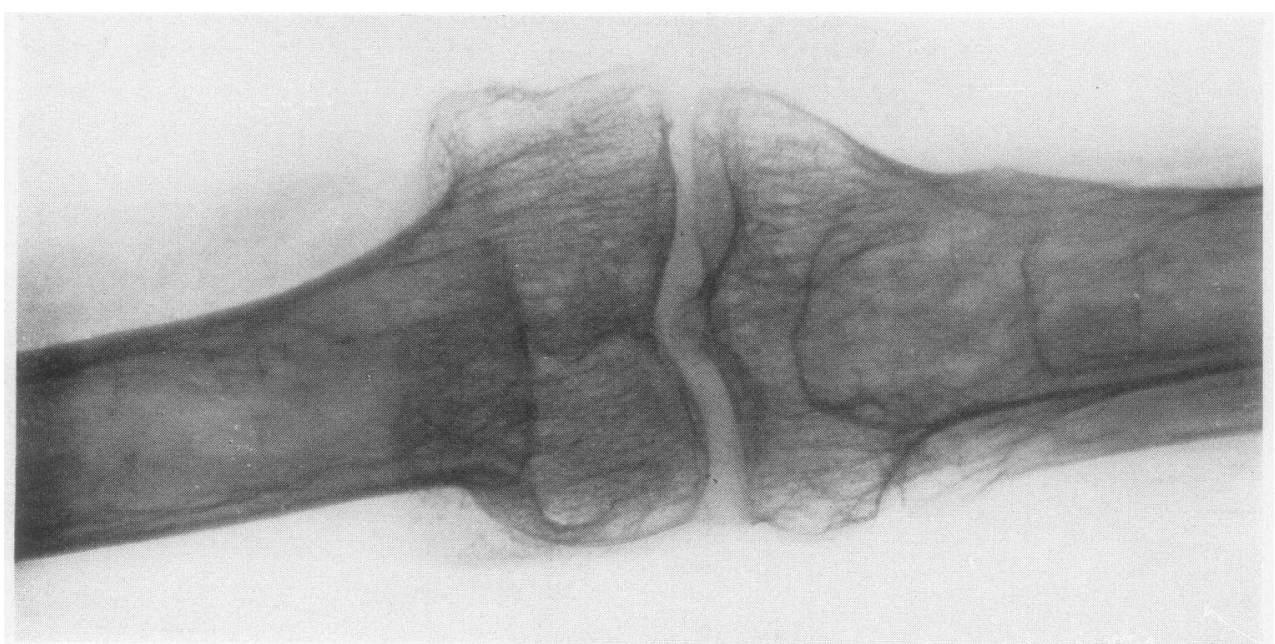

Fig. 5. X-ray of Left Knee Region. 
dosage was sixty drops of the $250 \mathrm{D}$ preparation a day (twenty drops three times a day), and for the last three periods she received ninety drops a day divided into three equal doses. A study of the data shows that during the last two of the five viosterol periods the excretion of both calcium and phosphorus in the urine increased significantly, whereas there was a decrease in the amount in the faeces; the increased urinary excretion, however, was so great as to swing the balance to the negative side. Except for the increase of phosphorus in the urine, these results are similar to those obtained by Pugsley (9) in rats receiving large closes of irradiated ergosterol, relatively many times greater than those received by our patient. We are unable to offer an explanation for this effect.

Under this therapy the level of both elements in the serum tended to rise slightly, but did not exceed those observed in the preceding periods without medication.

\section{DISCUSSION}

In their monograph on the pathological findings in acromegaly, Cushing and Davidoff (10) emphasize the adenomatous changes found in the endocrine organs. In two of their cases, where the parathyroids were identified, in one a single parathyroid was found enlarged and showed microscopically evidence of proliferative activity; in the other, what was taken to be a central adenoma of the parathyroid was found. They were, however, unable to find in the literature any extensive reference to the state of the parathyroids in acromegaly, and point out that our knowledge of the function of the parathyroids is greater than our knowledge of their histopathology.

Our present studies fail to produce definite metabolic evidence of parathyroid hyperfunction, the criteria of which are now so well established (11) (12). The failure to demonstrate an increase of the serum calcium above $11 \mathrm{mgm}$. per $100 \mathrm{cc}$. or a decrease of the inorganic phosphorus below $4.1 \mathrm{mgm}$. per $100 \mathrm{cc}$. is evidence against the presence of this condition, even in its less typical forms (13). On the other hand it is obvious that the excretion of calcium in the urine is relatively greater in amount than that observed in normal individuals on similar intakes of calcium, and is one of the factors which tend to produce a negative balance when the intake is low. As the diets were approximately neutral this increased excretion cannot be due to "uncovered" acid radicles.

Unfortunately in none of the cases here reviewed are figures given for calcium and phosphorus in the serum. The cases of Edsall and Miller (6) and Medigreceanu and Kristeller (8) show an excretion of calcium in the urine which approaches the levels seen in frank hyperparathyroidism; those of Von Moraczewski (5) and Oberndörffer (7) are nearer to those found in our case. Von Moraczewski's second observation and Bergeim, Stewart and Hawk's (1) case show levels similar to those found in normal subjects.

Whether a mere increase of excretion of calcium in the urine, without changes in the calcium and phosphorus levels in the serum, can be taken as evidence of hyperparathyroid activity or not is at present a controversial subject, with the bulk of the evidence favouring the negative. With the present criteria, our case, lacking the abnormai findings in the serum, and showing only a moderate increase in urinary excretion, cannot be classified as showing true evidence of parathyroid hyperfunction.

The calcium metabolism is similar in our case to that observed in Cushing's (14) twelfth case of pituitary basophilism in that both show a normal level in the serum, and a moderately increased excretion in the urine. The serum phosphorus, however, in Cushing's case was at a definitely low level, whereas it was within normal limits in ours.

It is a well recognized fact that rarefaction of the bones may result from hyperthyroidism (15), a condition which might be considered as an etiological factor in this case. There is, however, nothing in the history or physical condition to suggest past or present hyperthyroidism, the patient has never been under thyroid medication, and the basal metabolic rate falls within normal limits. From the metabolic point of view the excretion of calcium and phosphorus is also at a much lower level than that found in hyperthyroidism.

The occurrence in acromegaly of such marked rarefaction of the bones as is present in our case must be unusual, as we have been unable to find any reference to it in the literature. Studies of the histopathological changes found in the bones 
of acromegalics $(10,16,17,18,19)$ indicate that the skeletal growth is due chiefly to new compact bone laid down by the periosteum, with coincidental resorption of the old bone on the inner side, leading to enlargement of the marrow cavities in the long bones, accessory sinuses in the face, and general broadening of the flat bones. In the thorax, growth takes place by the formation of new bone at the end of the ribs through proliferation and subsequent ossification of the costal cartilages. Most of these changes are evident in x-ray studies of our case. Thus, although the epiphyses are closed, the skeleton of the acromegalic grows in breadth, the calcium and phosphorus being laid down in the newly ossified tissue and resorbed from the old bone, in a process which appears from the biochemical viewpoint to be similar to that involved in the growth of bone, in normally growing young animals.

It is well established that the young growing animal, or one in the latter part of pregnancy, is sensitive to alterations in the calcium or phosphorus or vitamine intake, and a deficiency in these elements due to a poorly balanced diet or to poor absorption may lead to rickets or osteomalacia with generalized rarefaction of the bones.

In our case Diet I is deficient in calcium for the average adult, Diet II probably so, and Diet III theoretically sufficient. The increased excretion of calcium and phosphorus in the urine together with the change from negative to positive balance with increase in intake would tend to show that in this case absorption is not at fault. The failure of viosterol therapy to increase the retention of calcium may be taken as eviclence that the lack of vitamine $\mathrm{D}$ is not a significant factor, at least with these diets. Our studies show that in her present condition, when the overgrowth of bone is not rapid, though $\mathrm{x}$-ray suggests that it is still proceeding, the patient needs a daily intake of approximately one gram of calcium to remain in positive balance; with less than this there is actual calcium loss. While it is obviously impossible to obtain a reliable dietary history extending over the past twenty years, we feel that the most rational explanation of the bony rarefaction is that during the prolonged period of overgrowth of the skeleton stimulated by pituitary dysfunction, the calcium-phosphorus intake has been insufficient, when associated with the increased urinary excre- tion of these elements, to establish a positive balance of sufficient degree to meet the demands of the growing bones. In consequence these have been laid down in a state of incomplete calcification, a state which has not since been remedied by any change in the diet sufficient to produce a positive balance, and promote storage of calcium triphosphate in the bones.

\section{SUMMARY}

Calcium and phosphorus metabolism has been studied in an advanced case of acromegaly showing generalised rarefaction of the bones. These findings are compared with others from the literature, in which, however, no other reports of rarefaction of the bones have been found.

It is suggested that in this case the osteoporosis is due to an insufficient intake of calcium and phosphorus associated with a moderate increase in excretion in the urine during the years of acromegalic growth; no complete evidence has been found to support the view that parathyroid or thyroid hyperfunction plays any part in the process.

\section{BIBLIOGRAPHY}

1. Bergeim, O., Stewart, F. T., and Hawk, P. B., A study of the metabolism of calcium, magnesium, sulphur, phosphorus and nitrogen in acromegaly. J. Exper. Med., 1914, 20, 218.

2. Sherman, H. C., and Gettler, A. O., The balance of acid-forming and base-forming elements in foods, and its relation to ammonia metabolism. I. Biol. Chem., 1912, 11, 323.

3. Scriver, W. de M., and Venning, E., Observations upon the calcium and phosphorus metabolism in certain diseases of bone. J. Clin. Invest., 1934, 13, 139.

4. Schiff, A., Hypophysis and thyreoidea in ihrer Einwirkung auf den menschlichen Stoffwechsel. II ien. klin. Wchnschr.. 1897, 10, 277.

5. Von Moraczewski, W. D., Stoffwechsel bei Akromegalie unter der Behandlung mit Sauerstoff, Phosphor, etc. Ztschr. f. klin. Med., 1901, 43, 336.

6. Edsall, D. L., and Miller, C. W., A contribution to the chemical pathology of acromegaly. Univ. Penn. Med. Bull., 1903-04, 16, 143.

7. Oberndörffer, E., Ueber den stoffwechsel bei Akromegalie. Ztschr. f. klin. Med., 1908, 65, 6.

8. Medigreceanu, F., and Kristeller, L., General metabolism with special reference to mineral metabolism in a patient with acromegaly complicated with glycosuria. J. Biol. Chem., 1911, 9, 109.

9. Pugsley, L. I., The effect of parathyroid hormone 
and of irradiated ergosterol on calcium and phosphorus metabolism in the rat. J. Physiol., 1932, 76, 315.

10. Cushing, H., and Davidoff, L. M., The pathological findings in four autopsied cases of acromegaly with a discussion of their significance. Monographs Rockefeller Institute for Medical Research, 1927, No. 22.

11. Bauer, W., Hyperparathyroidism. A distinct disease entity. J. Bone and Joint Surg., 1933, 15, 135.

12. Compere, E. L., The rôle of the parathyroid glands in diseases associated with demineralization of the human skeleton. J. Bone and Joint Surg., 1933, $15,142$.

13. Albright, F., Aub, J. C., and Bauer, W., Hyperparathyroidism, a common and polymorphic condition as illustrated by seventeen cases from one clinic. J. A. M. A., 1934, 102, 1276.
14. Cushing, H., Further notes on pituitary basophilism. J. A. M. A., 1932, 99, 281.

15. Aub, J. C., Bauer, W., Heath, C., and Ropes, M., Studies of calcium and phosphorus metabolism: III. The effects of the thyroid hormone and thyroid disease. J. Clin. Invest., 1929, 7, 97.

16. Brooks, H., Acromegalia. Arch. Neurol. and Psychopath., 1898, 1, 485.

17. Schultze, F., and Fischer, B., Zur Lehre von der Akromegalie und Osteoarthropathie hypertrophiante. Mitt. a. d. Grenzgeb. d. Med. u. Chir., 1912, 24, 607.

18. Reinhardt, A., and Creutzfeldt, H. G., Beitrag zur Lehre von der Akromegalie. Beitr. z. path. Anat. u. z. allg. Path., 1913, 56, 465.

19. Erdheim, J., Über Wirbelsäulenveränderungen bei Akromegalie. Virchow Arch. f. path. Anat., 1931, 281, 197. 